\title{
Adenylate Cyclase 1 as a Key Actor in the Refinement of Retinal Projection Maps
}

\author{
Anne Ravary, ${ }^{1}$ Aude Muzerelle, ${ }^{1}$ Denis Hervé, ${ }^{3}$ Vincent Pascoli, ${ }^{3}$ Kim Nguyen Ba-Charvet, ${ }^{1}$ Jean-Antoine Girault, ${ }^{3}$ \\ Egbert Welker, ${ }^{2}$ and Patricia Gaspar ${ }^{1}$ \\ ${ }^{1}$ Institut National de la Santé et de la Recherche Médicale Unite 106, Institut Federatif de Neurosciences, Hôpital Pitié-Salpêtrière, 75651 Paris, France, \\ ${ }^{2}$ Institut de Biologie Cellulaire et Morphologie, University of Lausanne, 1005 Lausanne, Switzerland, and Institut National de la Santé et de la Recherche \\ Médicale Unite 536, Institut du Fer à Moulin, 75005 Paris, France
}

cAMP occupies a strategic position to control neuronal responses to a large variety of developmental cues. We have analyzed the role of calcium-stimulated adenylate cyclase 1 (AC1) in the development of retinal topographic maps. AC1 is expressed in retinal ganglion cells (RGCs) from embryonic day 15 to adulthood with a peak during the first postnatal week. At that time, the other calcium-stimulated AC, $\mathrm{AC}$, is expressed in the superior colliculus (SC) but not in the RGCs. In mice of the barrelless strain, which carry an inactivating mutation of the AC1 gene, calcium-stimulated AC activity is reduced by $40-60 \%$ in the SC and retina. RGC projection maps were analyzed with a variety of anterograde and retrograde tracers. After an initially normal development until postnatal day 3 , retinal fibers from the ipsilateral and contralateral eye fail to segregate into eye-specific domains in the lateral geniculate nucleus and the SC. Topographic defects in the fine tuning of the retinotectal and retinogeniculate maps are also observed with abnormalities in the confinement of the retinal axon arbors in the anteroposterior and mediolateral dimensions. This is attributable to the lack of elimination of misplaced axon collaterals and to the maintenance of a transient ipsilateral projection. These results establish an essential role of ACl in the fine patterning of the retinal map. Calcium-modulated cAMP production in the RGCs could constitute an important link between activitydependent changes and the anatomical restructuring of the retinal terminal arbors within central targets.

Key words: cAMP; dLGN; superior colliculus; retinal ganglion cells; developmental plasticity; barrelless

\section{Introduction}

cAMP is an essential second messenger for the development and plasticity of the nervous system, because it is implicated in a wide range of trophic responses as well as in activity-dependent changes of synaptic transmission (Huang et al., 1994; Weisskopf et al., 1994). cAMP signaling mediates the effects of a number of guidance and trophic molecules. In vitro, cAMP modulates the survival of retinal ganglion cells (RGCs) and spinal motor neurons (Meyer-Franke et al., 1995, 1998) and modifies axon growth responses to attractive or repulsive cues (Song et al., 1997, 1998; Cai et al., 2001).

The visual pathway offers an ideal system to examine the developmental role of cAMP in vivo. The formation of ordered topographic maps, from the retina to the superior colliculus (SC) and the dorsal lateral geniculate nucleus (dLGN), involves a sequence of events that can all be potentially modified by altered cAMP signaling. The early formation of the map requires that RGC axons be guided to their targets by chemorepulsive and chemoattractive cues (Mason

\footnotetext{
Received 0ct. 15, 2002; revised Dec. 11, 2002; accepted Dec. 12, 2002

This work was supported by Institut National de la Santé et de la Recherche Médicale and the Ministère de la Recherche (Action Concerteé Incitative Développement Grant 141). A.R. was supported by a fellowship from the Ecole Polytechnique. K.N.B.-C. was supported by a fellowship from La Fondation de la Recherche Médicale. E.W. was supported by Swiss National Swiss Foundation Grant 3100-062112.00. We thank Constantino Sotelo for constant support; Chantal Alvarez for technical help; Guy Chan, Daniel Storm, and Nicole Defer for the gift of the AC probes; Louise Upton for help in setting up the tracing experiments; and Olivier Cases, Serge Marty, Nicole Ropert, and Richard Miles for critical reading of this manuscript.

Correspondence should be addressed to Patricia Gaspar, Institut National de la Santé et de la Recherche Médicale Unite 106, Hôpital Pitié-Salpêtrière, 47 Boulevarde de I'Hôpital, 75651 Paris Cedex 13, France. E-mail: patricia.gaspar@u106.eu.org.

Copyright $\odot 2003$ Society for Neuroscience $\quad 0270-6474 / 03 / 232228-11 \$ 15.00 / 0$
}

and Erskine, 2000). Then, within the target nuclei, graded expression of repulsive molecules dictates the establishment of a rough projection map (Wilkinson, 2001), which is refined by activity-dependent mechanisms (Constantine-Paton and Cline, 1998; Penn et al., 1998). Recent observations have highlighted the role of cAMP in the generation of spontaneous activity in the retina and in the activitydependent separation of afferents from the ipsilateral and contralateral eye in the dLGN (Stellwagen et al., 1999; Stellwagen and Shatz, 2002).

Intracellular cAMP levels result from a balance between synthesis by adenylate cyclases (ACs) and degradation by phosphodiesterases. At least 10 different ACs are expressed in the brain. The AC isoforms are encoded by different genes but have a high degree of homology and share identical catalytic sites. However, each isoform has unique regulatory properties, being modulated by $G$-proteins $\left(G_{s}, G_{i}\right.$, or $\left.G_{q}\right)$ or directly modulated by calcium alone or a combination of both signals (for review, see Cooper et al., 1995). AC1 and AC8 are of particular interest for studies on neural plasticity, because they are the only ACs to be directly stimulated by calcium and calmodulin in vivo and are highly expressed in the brain.

AC1-knock-out (KO) mice or mice carrying a spontaneous mutation of the AC1 gene, the barrelless (brl) mouse strain (Welker et al., 1996; Abdel-Majid et al., 1998), have altered development of the thalamocortical projections and do not develop normal barrel patterns in the cortex (Welker et al., 1996). In the present analysis, we report that the refinement of the retinal projection map is altered in the brl mice. Early development of the retinal projection is normal, indicating that $\mathrm{ACl}$ is not necessary for the 
initial guidance of retinal axons to their targets. Later refinement in the positioning of the retinal axons during postnatal life is disturbed. This concerns both the formation of eye-specific domains in the SC and dLGN and the nasotemporal ordering of the retinotectal map. In both cases, an immature diffuse pattern of projections is retained. During this developmental period, AC1 is the only calciumstimulated $\mathrm{AC}$ in the RGCs. We propose that $\mathrm{ACl}$ acts presynaptically in the RGCs to modulate the reshaping of axon terminal arbors in the retinofugal projections.

\section{Materials and Methods}

Animals. The brl mutation occurred spontaneously in the nor strain (Van der Loos et al., 1986; Welker et al., 1996) at the university of Lausanne and has been subsequently characterized as an AC1 inactivation (AbdelMajid et al., 1998). brl homozygous mice as well as NOR mice were obtained from the Lausanne breeding stock. Additional wild-type (WT) mice with a Swiss background were purchased from Janvier. Animals were analyzed at different developmental ages ranging from embryonic day 14.5 (E14.5) to postnatal day 21 (P21) and as adults (5 weeks-4 months). The morning of the vaginal plug was counted as E0.5, and the day of birth was counted as P0.

The experiments were performed in accordance with European Communities Council Directive 86/609/EEC. For all experiments, the adult mice were anesthetized with $4 \%$ chloral hydrate $(0.1 \mathrm{ml} / 10 \mathrm{mg}$ of body weight, i.p.), and $\mathrm{P} 0-\mathrm{P} 8$ pups were anesthetized by hypothermia.

In situ hybridization. Normal mice aged E15, E17, P0, P3, P5, P8, and adults were perfused with $4 \%$ paraformaldehyde in $0.12 \mathrm{M}$ phosphate buffer $(\mathrm{PB})$. Whole heads or dissected retinas and brains were postfixed $5-24 \mathrm{hr}$, cryoprotected overnight (10\% sucrose in $\mathrm{PB})$, embedded in $7.5 \%$ gelatin and $10 \%$ sucrose $\left(37^{\circ} \mathrm{C}\right.$ for $\left.30 \mathrm{~min}\right)$, frozen at $-40^{\circ} \mathrm{C}$, and serially cut into $20-\mu \mathrm{m}$-thick sections on a cryostat.

The $3.5 \mathrm{~kb} \mathrm{AC} 1$ probe, corresponding to the full length of the bovine AC1 gene, was kindly provided by Dr. Guy Chan (D. Storm Laboratory, Department of Pharmacology, University of Washington, Seattle, WA). Another AC1 probe (corresponding to 1501-2012 bp of the bovine gene) was used in parallel and provided better results on the adult material. The AC8 riboprobe was kindly provided by Dr. Nicole Defer (Institut National de la Santé et de la Recherche Médicale Unite 99, Créteil, France). Different protocols of hybridization were used: the ${ }^{35} \mathrm{~S}$-UTP-labeled probe, as described by Lebrand et al. (1998), and the digoxigenin-UTPlabeled probe (Roche Molecular Biochemicals, Manheim, Germany) (using a riboprobe system; Promega Madison, WI) as follows. Mounted sections were postfixed for $10 \mathrm{~min}$ in $4 \%$ paraformaldehyde in PBS, rinsed in PBS, treated with proteinase $\mathrm{K}(5 \mu \mathrm{g} / \mathrm{ml})$ for $2-5 \mathrm{~min}$, fixed and rinsed again, acetylated, treated with $1 \%$ Triton X-100 for $30 \mathrm{~min}$, and rinsed in PBS. After $2 \mathrm{hr}$ of prehybridization in hybridization buffer ( $50 \%$ formamide, $1 \mathrm{mg} / \mathrm{ml}$ yeast tRNA, $0.5 \mathrm{mg} / \mathrm{ml}$ salmon sperm, $5 \times$ Denhardt's solution, and $5 \times$ SSC), the sections were hybridized with the probe at $72^{\circ} \mathrm{C}$ overnight. The following day, sections were rinsed in $0.2 \times$ SSC and in B1 buffer (0.1 M Tris, pH 7.5, 0.15 M NaCl, and $0.1 \%$ Tween 20 ) with $10 \%$ normal goat serum (NGS). They were incubated with the alkaline phosphatase-coupled anti-digoxigenin antibody (1:5000, 1\% NGS in B1; Roche Diagnostics) overnight at room temperature. Sections were rinsed in $\mathrm{B} 1$, and the alkaline phosphatase activity was revealed [incubation with 4-nitroblue tetrazolium chloride and 4-bromo,-3chloro-2-indoyl phosphate (Roche Diagnostics) in 0.1 м Tris, $\mathrm{pH}$ 9.5, 0.1 $\mathrm{M} \mathrm{NaCl}$, and $50 \mathrm{~mm} \mathrm{MgCl}_{2}$ ]. Sections were mounted in Mowiol 4-88 (Calbiochem, La Jolla, CA) and kept at $-20^{\circ} \mathrm{C}$.

Adenylate cyclase activity assay. Homogenates of the retina and the SC were prepared by pooling the dissected brain structures from five animals for each age and for each genotype. The SC and retinas were dissected from WT and $b r l$ mice at P1, P3, P6, P8, and 6 weeks. The samples were homogenized in ice-cold H buffer (20 mM Tris maleate, 2 mM EGTA, 0.5 mM dithiothreitol, $0.5 \mathrm{~mm}$ PMSF, and $5 \mu \mathrm{g} / \mathrm{ml}$ leupeptin) with a potter. The nuclei were removed with a 2 min centrifugation $(600 \times g)$; the supernatants were centrifuged at $100,000 \times g(10 \mathrm{~min})$; and the membranes were resuspended in $\mathrm{H}$ buffer. The membranes were assayed in I buffer (25 mu Tris maleate, $0.625 \mathrm{~mm}$ ATP, $0.05 \mathrm{mCi} / \mathrm{ml}\left[\alpha-{ }^{32} \mathrm{P}\right] \mathrm{ATP}, 1$ $\mathrm{mm} \mathrm{MgSO}_{4}, 10 \mathrm{~mm}$ creatine phosphate, $0.3 \mathrm{mg} / \mathrm{ml}$ creatine kinase, 2.5 $\mu \mathrm{M}$ calmodulin, $1 \mu \mathrm{M}$ GTP, $10 \mathrm{~mm}$ theophyllin, $1 \mathrm{~mm}$ EGTA, and 0.4 $\mu \mathrm{l} / \mathrm{ml}\left[{ }^{3} \mathrm{H}\right] \mathrm{cAMP}$ ) with different concentrations of $\mathrm{CaSO}_{4}$ (concentrations of free $\mathrm{Ca}^{2+}$ calculated with the Bound and Determined computer program; Brooks and Storey, 1992) or $50 \mu \mathrm{M}$ forskolin (Sigma, St. Louis, $\mathrm{MO}$ ) for $7 \mathrm{~min}$ at $30^{\circ} \mathrm{C}$. The reaction was stopped by cooling on ice and by adding a stop solution (50 mm Tris, $5 \mathrm{~mm}$ ATP, $5 \mathrm{~mm} \mathrm{cAMP}$, and $1 \%$ SDS) in large excess. cAMP was recovered by using Dowex and neutral alumina columns (Salomon et al., 1974). Each point is the mean of triplicate assays from one homogenate. Values of enzymatic activity are expressed per milligram of total protein (measured with the BCA assay).

Anterograde tracing of retinal axons. To label the entire retinal projection from one eye, intraocular horseradish peroxidase (HRP) injections were made in adults and in $\mathrm{P} 2$ mice; $1.5-4 \mu \mathrm{l}$ (depending on the age of the mouse) of $60 \%$ horseradish peroxidase (type VI; Sigma) in physiological saline was injected into the vitreous chamber of the left eye with a Hamilton (Reno, $\mathrm{NV}$ ) syringe. Twenty four hours later, mice were anesthetized and perfused through the aorta with $5-20 \mathrm{ml}$ of saline followed by $40-150 \mathrm{ml}$ of ice-cold $1 \%$ paraformaldehyde and $1.25 \%$ glutaraldehyde in $\mathrm{PB}, \mathrm{pH}$ 7.4. Brains were cryoprotected in $30 \%$ sucrose and $\mathrm{PB}$ overnight at $4^{\circ} \mathrm{C}$, frozen, and serially cut into $40 \mu \mathrm{m}$ coronal sections (50 $\mu \mathrm{m}$ for pup brains), and sections were collected in ice-cold PB. Sections were processed within $24 \mathrm{hr}$, as previously described (Upton et al., 1999, 2002).

In eight cases (four of each genotype), anterograde tracers coupled to different fluorochromes were used. In each animal, Alexa 488 conjugated to cholera toxin subunit $\beta$ (CTB; Molecular Probes, Eugene, OR) was injected into one eye, and Alexa 594 CTB was injected into the other eye. Fluorochromes were diluted $(3 \mathrm{mg} / \mathrm{ml})$ in $20 \%$ saline and sucrose. Three microliters of this solution were injected into the eyes. After a $2 \mathrm{~d}$ survival, the mice were perfused, and the brains were postfixed overnight and cryoprotected in $30 \%$ sucrose. The brains were serially cut on a freezing microtome to $40-\mu \mathrm{m}-$ thick sections, mounted in Mowiol, and directly observed.

To analyze the topography of the retinal projections, small injections of carbocyanine were made to label a small group of retinal ganglion cells in mature (P21-P30) animals or in mouse pups (P2). After anesthesia, a small crystal of 1,1'-dioctadecyl-3,3,3',3'-tetramethyl-indocarbocyanine perchlorate (DiI; Molecular Probes) was inserted into the temporal or nasal margin of the retina. After a $1 \mathrm{~d}$ survival in pups (P3) or a $2 \mathrm{~d}$ survival in adults, the mice were perfused ( $50-200 \mathrm{ml}$ of $4 \%$ paraformaldehyde in 0.12 $\mathrm{M}$ phosphate buffer). The retinas were dissected out and flattened to select the cases in which only a limited number of retinal axons converged toward the optic disk. The corresponding brains were removed, postfixed at least $24 \mathrm{hr}$, and serially cut into $140 \mu \mathrm{m}$ parasagittal (SC) or coronal (thalamus) sections with a Vibratome (Leica, Nussloch, Germany) and mounted in Mowiol 4-88 (Calbiochem).

Quantification of the retinal projection abnormalities. Images were acquired with a digital camera (Princeton Instruments) to measure the extent of the retinal projections (Meta Imaging program). The area covered by the HRP-labeled terminals in the dLGN was measured in complete series of coronal sections through the dLGN of WT and $b r l$ adult mice as previously described (Upton et al., 2002). The limits of the ipsilateral projection were outlined on the computer screen. The total volume of the dLGN was determined from the same serial sections by delimiting the external contours of HRP labeling in the contralateral dLGN. This value includes the area of contralateral HRP labeling as well as any unlabeled territory in the center.

Additional measures of the ipsilateral projection were done in cases with injections of different CTB-coupled fluorochromes into each eye. In addition to allowing an evaluation of the extent of overlap of projections from both eyes, CTB permits the evaluation of the space occupied by axon terminals exclusively, contrary to HRP, which shows both axon tracts and terminals. We first measured the size of the dLGN and the size of the ipsilateral patch as described above, except that the measures were done from three consecutive coronal sections, at the midlevel of the dLGN (the entire series was analyzed in the HRP cases). Then we evaluated the area occupied by the ipsilateral terminals by thresholding the image taken with the red excitation filter using a $20 \times$ objective and at a final magnification of $100 \times$ (injections of Alexa 594 CTB conjugate into the ipsilateral eye). A threshold value was determined on the control 


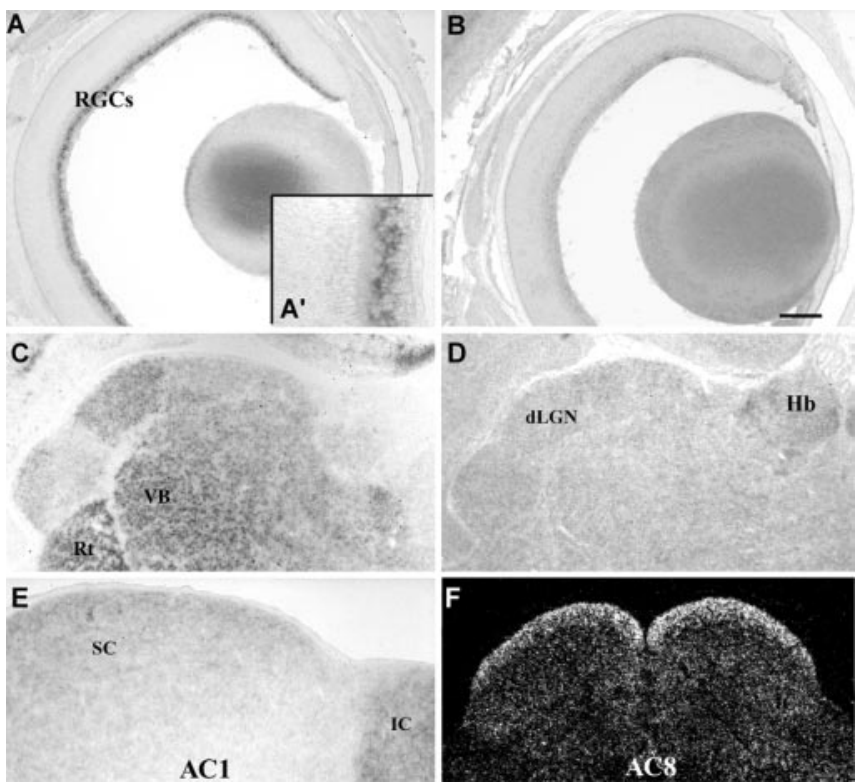

Figure 1. Localization of $A C 1$ and $A C 8 m R N A$ in the developing visual system. $A C 1$ (left) and AC8 (right) mRNAs were revealed with digoxigenin-labeled probes $(A-E)$ or with radiolabeled probes $(F)$ on cryostat sections from $P 3$ pups (WT mice). $A, B$, In the retina, strong homogenous AC1 expression $(A)$ is detected in all the RGCs as shown at a higher magnification $\left(A^{\prime}\right)$ and appears to be limited to this neuronal population. With the AC8 probe, no specific signal is detected $(B)$; the diffuse gray stain is identical to that obtained with control sense probes. $C, D$, In the thalamus, $\mathrm{AC} 1$ gene expression $(C)$ was detected in the $\mathrm{dLGN}$, the ventrobasal thalamic nucleus $(V B)$, and the reticulans $(R T)$ but there is no visible $A C 8$ signal. Some AC8 expression is observed in the habenula $(\mathrm{Hb})$ (the sections are in the coronal plane; medial is to the right, and dorsal is at the top). E, A very low level of AC1 is detected in the SC, contrasting with the high expression that is visible in the inferior colliculus $(I C)$. F, Significant AC8 expression is detected in the upper layers of the $S C$. Scale bar: $A-F, 0.2 \mathrm{~mm} ; A^{\prime}, 0.05 \mathrm{~mm}$.

cases to minimize any saturation of the signal. This fixed threshold was used for all the cases. To determine the extent of overlap between the ipsilateral and contralateral fibers, we measured the area shared by the Alexa 594 and 488 labeling, which appears yellow on composite images (see Fig. $4 D$ ). This is not a colocalization, strictly speaking, because each terminal contains only a single dye (as can be checked with confocal microscopy), but it corresponds to the topographic overlap within the plane of a $40-\mu \mathrm{m}$-thick section. To measure the area of overlap, we used the "product" function between the red and green images (Photoshop version 6.0 software). The pixels occupied by the resulting image were then quantified using Metamorph software.

To provide a quantitative description of the ipsilateral retinal projections in the SC, we used three criteria that have been fully described and validated in a previous study (Upton et al., 2002). In complete rostrocaudal series of sections through the SC, we determined (1) the number of labeled clusters, (2) the mediolateral extension of the ipsilateral projection, and (3) the dorsoventral extent of the ipsilateral projection in the rostral SC, which was quantified as follows: the area containing the HRP labeling was delimited on the second, fifth, and ninth sections in the complete series, and the mean height was calculated by dividing the area by the width ( $n=5$ or 7 per genotype).

Quantification of the retinal axon arbor terminal area after small carbocyanine injections was done on complete series of sagittal or coronal sections through the SC. Only injections of a comparable size in the nasal or temporal retina were selected for this quantification. In sagittal sections, the rostrocaudal extent of the retinal axon arbor terminal area was measured on every section, and the longest value was retained. The measure of the rostrocaudal extent of the SC was done on the same section to provide an estimate of the percentage of SC length that is occupied by the projection. In the case of temporal injections, we also counted the number of RGC axons that extended into the caudal quarter of the SC. Furthermore, an estimate of the mediolateral extent of the terminal arbors

\section{A}

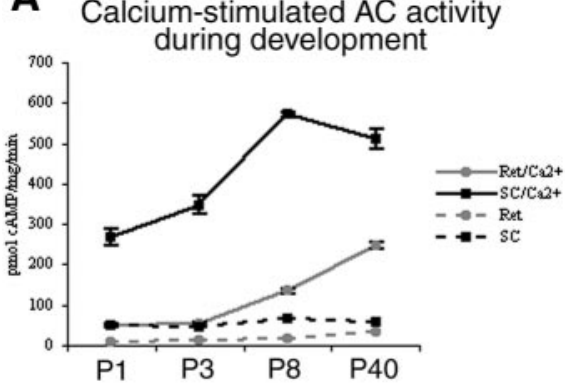

B

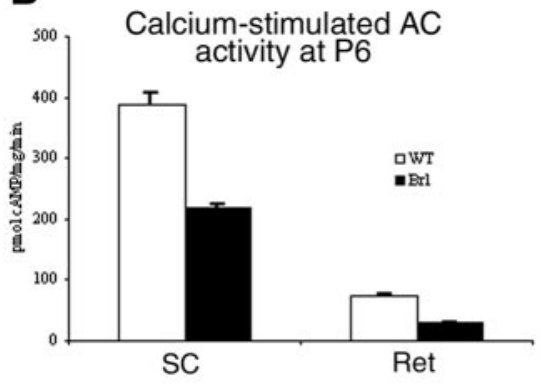

\section{Forskolin-stimulated AC}

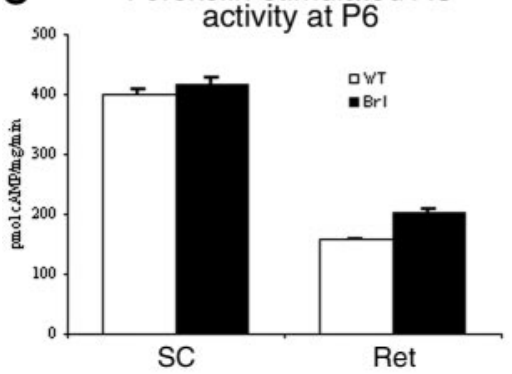

Figure 2. AC activity in the developing retinotectal system. A, Calcium-stimulated activity in the SC (black squares) and in the retina (gray circles) during development in the WT mice. The solid curves show the $\mathrm{AC}$ activity in the presence of $300 \mathrm{~nm}$ calcium, and the dotted curves show the basal $\mathrm{AC}$ activity without free calcium. Calcium-stimulated $\mathrm{AC}$ activity is higher in the $\mathrm{SC}$ than in the retina at all the ages tested. $B$, Calcium-stimulated activity (in the presence of $300 \mathrm{~nm}$ calcium) in WT mice (white bars) and brl mice (black bars) aged P6 in the SC and the retina. The activity is decreased by $40 \%$ in both structures. This was replicated in two independent experiments. C, AC activity in the presence of forskolin $(50 \mu \mathrm{M})$ in WT and br/ mice aged P6 in the SC and the retinas. As shown in two independent experiments, there was no change or only a slight increase in the total level of $\mathrm{AC}$ in $\mathrm{SC}$ and retinas. $\mathrm{AC}$ activity is presented as picomoles of CAMP synthesized per milligram of total protein per minute. Error bars indicate SD among triplicates.

was provided by counting the number of parasagittal sections $(n)$ in which carbocyanine-labeled fibers were detectable (lateral extent $=n \times$ $140 \mu \mathrm{m})$. The mediolateral extent was also measured directly in another series of cases that were sectioned in the coronal plane.

All statistical evaluations were calculated with the ANOVA test on four to seven cases.

Retrograde labeling of ipsilaterally and contralaterally projecting RGCs. To localize and quantify the RGCs that project ipsilaterally or contralaterally, large injections of fluorogold (FG; Fluorochrome Inc.) were made unilaterally into the optic tract at the level of the dLGN on one side of the brains of 1-month-old mice. Mice were anesthetized and placed in a stereotaxic frame. Five percent FG $(0.2 \mu \mathrm{l})$ was injected $2.5 \mathrm{~mm}$ posterior to bregma, $2.2 \mathrm{~mm}$ lateral to the midline, and $2.5 \mathrm{~mm}$ deep to the surface. Animals were perfused $48 \mathrm{hr}$ later. Retinas were dissected, flattened, and postfixed between a slide and a coverslip $(1 \mathrm{hr})$. The entire retina was then photographed $(400 \times)$ to measure the area of the ipsilateral crescent (the area containing a high density of ipsilaterally projecting RGCs). The density of labeled RGCs was measured from three micrographs (3200X) 


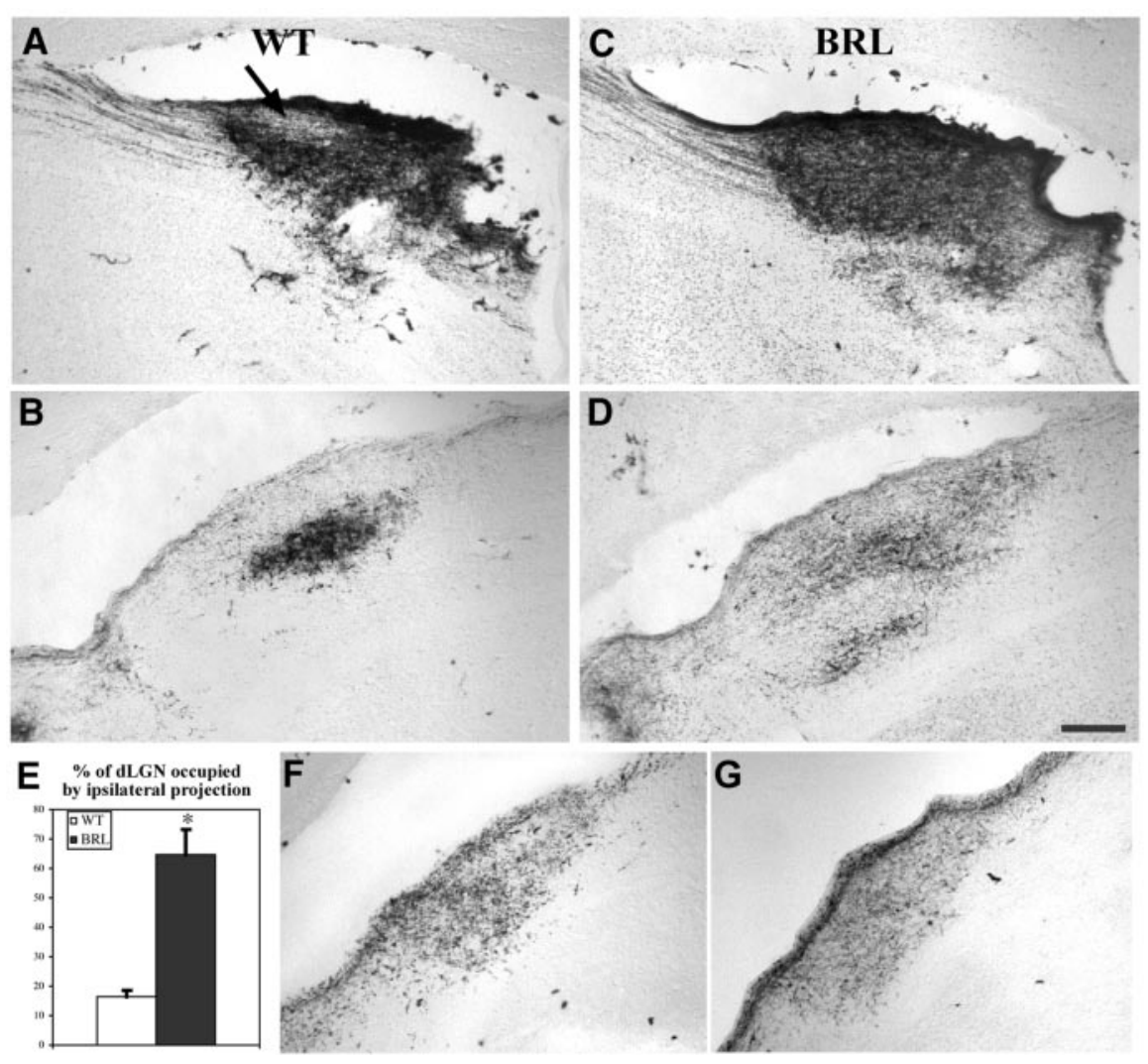

Figure 3. Abnormal segregation of the ipsilateral and contralateral retinal axons in the $\mathrm{dLGN}$ of $b r /$ mice. Retinal projections were labeled with HRP injected into one eye in adult $(A-D)$ and $P 3(F-G)$ mice. $A, B$, In WT mice, the contralateral retinal fibers $(A)$ fill the entire dLGN, leaving a small unlabeled territory in the central region of the dLGN (arrow), whereas the ipsilateral retinal projections $(B)$ are distributed in a dense mediolateral patch. $C, D$, In the $b r /$ mice, the contralateral retinal axons $(C)$ fill the entire dLGN without leaving a gap, whereas the ipsilateral retinal axons $(D)$ are very loosely and widely distributed in the dLGN. $E$, The fraction of the total dLGN volume that is occupied by the ipsilateral terminals was measured on complete series of sections through the dLGN. The volume occupied by the ipsilateral RGCs is significantly larger in the br/ mice (black bars) than in the WT mice (open bars). The mean values and SDs are calculated from five cases of each genotype. *Significant difference (ANOVA, $p<0.05$ ). $F, G$, Ipsilateral retinal projections to the dLGN in P3 mice showing a similar widespread distribution in both the WT $(F)$ and the $b r I(G)$ strains ( $n=4$ for each genotype). Scale bar, $0.1 \mathrm{~mm}$.

within the ipsilateral crescent and from three micrographs in the central contralateral retina. Labeled RGCs outside the crescent were counted individually using an ocular grid.

Similar analyses were done in P3 pups. Diamidino yellow (DY; Sigma) was used in place of FG in pups. Indeed, at this age, FG but not DY tended to diffuse bilaterally from the injection site. Pups were anesthetized by hypothermia, and the cortex above the optic tract was removed by aspiration. A solution of $2 \%$ DY was pressure-injected into the optic tract using a fine-tipped glass micropipette. The hole was filled with Spongel (Laboratoires Houde), and the skin was joined with glue. Pups were perfused the next day, and the retinas were processed as described above.

\section{Results}

Localization of calcium-stimulated AC, AC1, and AC8 in the developing visual system

In situ hybridization of the $\mathrm{AC} 1$ gene was analyzed from E14.5 to adulthood. Beginning at E15, AC1 mRNA was found in the RGCs with no detectable signal in the other retinal cell types, such as the amacrine cells, the bipolar cells, or the photoreceptors. The same distribution was observed from E15 to adulthood, with a strong peak of expression from P1 to P8. At all ages, we found no evidence for a spatial gradient of expression within the retina (Fig. $1 A$ ).

In the SC, AC1 expression was very low and restricted to scattered neurons in the most superficial stratum of the SC. This contrasted with the high level of $\mathrm{ACl}$ expression in the inferior colliculus (Fig. 1E). In the dLGN, there was a medium level of AC1 mRNA during the late embryonic period and first postnatal week (Fig. 1C) that decreased in the mature dLGN (results not shown) (Matsuoka et al., 1997).

We compared AC1 distribution with AC8 mRNA expression, because AC8 is the only other AC that is directly stimulated by calcium and that could therefore directly compensate for loss of AC1 function (Wong et al., 1999). AC8 mRNA was not detectable in the developing retina from E14 to P3 (Fig. 1 B), and low levels of expression were noted at P8, increasing in the adult retina. In the adult retina, AC8 was however essentially localized to the photoreceptors, as previously noted (Quintyn et al., 1999), with very low expression in the RGCs. In the SC, moderate AC8 to high mRNA expression was found in the superficial layers (Fig. $1 F)$, with increasing expression until adulthood. In the dLGN, no AC8 mRNA expression was detected during the first postnatal week (Fig. 1D).

Thus AC1 and AC8 appear to have essentially complementary distributions in the developing visual system. Only AC1 is expressed in the RGCs during the period of refinement of the retinal projections, whereas AC8 is the main calciumstimulated AC expressed in the SC neurons.

\section{Adenylate cyclase activity in the developing visual system of WT and brl mice}

To determine the functional activity of the $\mathrm{AC} 1$ and AC8 genes, we measured the calcium-stimulated AC activity in the retina and the SC. AC activity was first measured on retinal and superior collicular membranes at P6 with different concentrations of calcium $(0.03-30 \mu \mathrm{M})$. At all the calcium concentrations tested, AC activity was eightfold higher in the SC than in the retina (data not shown). In the subsequent assays, calciumstimulated AC activity was measured in $300 \mathrm{~nm}$ calcium (the optimal concentration in our conditions) and compared with the calcium-free test condition. At P1 and P3, calcium-stimulated $\mathrm{AC}$ activity was low in the retina and then increased at $\mathrm{P} 8$ and in adults (Fig. $2 A$ ). In contrast, in the SC, AC activity was already high at birth and reached adult-like levels at P8 (Fig. $2 A$ ). Thus, from $\mathrm{P} 1$ up to $\mathrm{P} 3-\mathrm{P} 6$, the calcium-stimulated AC activity is low in the retina, contrasting with high activity levels in the SC. These observations, together with our finding that the AC1 mRNA is essentially expressed in the RGCs, suggests that at least some of the $\mathrm{AC} 1$ protein could be exported to the retinal terminals in the SC.

Next we examined the changes of AC activity in the $b r l$ mice. In the $\mathrm{P} 6 \mathrm{brl}$ mice, calcium-stimulated $\mathrm{AC}$ activity was reduced to background levels in the retina (Fig. $2 B$ ); in the SC, there was a $40 \%$ decrease in the activity levels (Fig. 2 B). This residual activity is likely to reflect AC8 activity.

We measured the total AC activity in the presence of forskolin 
Table 1. Distribution of ipsilateral and contralateral fibers in the dLGN of WT mice $(n=4)$ and $b r /$ mice $(n=1)$

\begin{tabular}{lllll}
\hline Mice & $\begin{array}{l}\text { Area of the dLGN } \\
\left(\times 1000 \mu \mathrm{m}^{2}\right)\end{array}$ & $\begin{array}{l}\text { Area of the } \\
\text { ipsilateral patch } \\
\left(\times 1000 \mu \mathrm{m}^{2}\right)\end{array}$ & $\begin{array}{l}\text { Area of labeled } \\
\text { ipsi terminals } \\
\left(\times 1000 \mu \mathrm{m}^{2}\right)\end{array}$ & $\begin{array}{l}\text { Area of overlap } \\
\left(\times 1000 \mu \mathrm{m}^{2}\right)\end{array}$ \\
\hline WT & $190 \pm 20$ & $28 \pm 7$ & $21 \pm 5$ & $2 \pm 1$ \\
brl & $200 \pm 30$ & $165 \pm 22^{*}$ & $65 \pm 17^{*}$ & $19 \pm 8^{*}$ \\
\hline
\end{tabular}

Values are means \pm SD.

*If significantly different from controls with ANOVA test, $p=0.05$

that activates all the ACs (except AC9). Forskolin-activated AC activity was high in the SC and retina at P6. This pattern is different from that observed after calcium stimulation, indicating that other ACs contribute to the total AC activity in the developing retina. In the $b r l$ mice, there was either no change or slightly increased levels of the forskolin-stimulated AC activity (Fig. 2C).

These findings indicate that the capacity for producing cAMP in response to calcium is severely reduced in the retina and SC of the $b r l$ mice, although the general capacity for producing cAMP in this system is not modified.

\section{Alteration of the distribution of ipsilateral and contralateral retinofugal projections in $\mathrm{brl}$ mice}

We first questioned whether the eye-specific distribution and segregation of retinal afferents in the SC and the dLGN is altered in the $b r l$ mice. This was done by two approaches, horseradish peroxidase ( $n=5$ for each genotype) and using two cholera toxin B-conjugated fluorochromes ( $n=4$ for each genotype). Quantitative evaluations were performed on the complete series of sections for HRP (Fig. 3E) and on a sample of three sections for the CTB-injected cases (Table 1).

Because there are important variations in the organization of the visual system among mouse strains (LaVail et al., 1978), we began by analyzing the organization of the projection in the WT genetic background of the $b r l$ mice (Fig. $3 A, B$ ). In this Swiss albino background, the ipsilateral projection consists of a small and dense dorsomedial patch that covers $15 \%$ of the total dLGN volume. The crossed retinal projection innervates the largest part of the dLGN, leaving a clear "gap" devoid of contralateral fibers only at the most rostral levels of the dLGN. The location of the gap corresponds to that of ipsilateral axons but is more limited (Fig. $3 A$ ). In cases with injections of different fluorochromes into each eye (Fig. $4 A$ ), a clear separation of the two terminal fields is visible (Fig. $4 C$ ). On the composite images (100× magnification), there is a very small amount of overlap, representing $10 \%$ of the ipsilateral projection (Table 1).

In the $b r l$ mice, the general morphology of the dLGN and its size (Table 1) are not modified. However, the distribution of the eye-specific projections is drastically altered (Fig. $3 C$ ). The contralateral projection is expanded and uniformly occupies the entire dLGN without leaving a zone of reduced fiber staining. Conversely the ipsilateral retinal axons extend broadly (Figs. 3D, 4B) to cover $65 \%$ of the dLGN volume as measured from HRP labeling (Fig. $3 E$ ). This difference is highly significant (ANOVA, $p<$ $0.05)$. The density of the ipsilateral fibers is reduced in comparison with the WT mice, suggesting that a similar amount of fibers could be present but more spread out. We evaluated the density of the ipsilateral projection after CTB labeling, which provides very sharp labeling of the axon terminals without preterminal labeling. The area occupied by the labeled terminals was compared with the area in which these terminals are distributed (contour of the patch; Table 1). The ratio of these two measures pro-
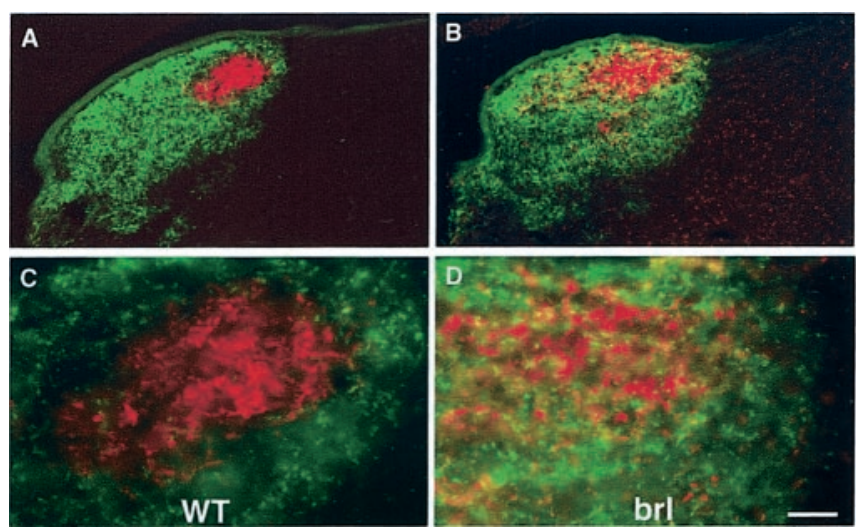

Figure 4. Abnormal segregation of the ipsilateral and contralateral retinal axons in the dLGN of $b r l$ mice. CTB coupled to Alexa 594 was injected into the ipsilateral eye and Alexa 488 was injected into the contralateral eye of adult WT and br/mice; sections through the midlevel of the $\mathrm{dLGN}$ were analyzed. $A, C$, In WT mice, retinal axon terminals originating in each eye terminate into nonoverlapping domains, and there appears to be an almost complete exclusion of the redand green-labeled terminals. $B, D$, in the $b r /$ mice, axon terminals originating from both eyes are intertwined over a large portion of the $\mathrm{dLGN}$; red-labeled ipsilateral axons are found in the midst of the contralateral projection zone; and, conversely, contralateral axons are found in the ipsilateral zone, with no clear frontiers between both labels. Scale bar: $A, B, 137 \mu \mathrm{m} ; C, D, 34 \mu \mathrm{m}$.

vides an estimate of the density of the terminals (a ratio of 1 is maximal). This showed a 50\% decrease in the fiber density in $\mathrm{brl}$ mice $(0.39 \pm 0.13)$ compared with control mice $(0.76 \pm 0.10)$. Double labeling with Alexa 488- and Alexa 595-labeled CTB also showed that there was a very close intertwining of the ipsilateral and contralateral retinal projections within areas of the dLGN that normally contain only ipsilateral or only contralateral retinal axons. We saw no evidence for a delimitation of microsegregated zones, contrarily to what has been observed in other mutants (Muir-Robinson et al., 2002). The estimated area of overlap between the ipsilateral and contralateral terminals was increased 10 -fold compared with controls (Table 1). However, such estimates do not allow evaluation of the degree of convergence or segregation at a cellular level. Clearly, a more careful analysis at the electron microscopic or electrophysiological level would be required to determine whether axons from both eyes converge onto a single neuron.

In the SC, the ipsilateral retinal projection is normally restricted to one layer, the stratum opticum (SO), where terminals form small dense clusters that are aligned along the mediolateral extent of the SC rostrally and become limited medially in the caudal SC. In the Swiss albino background, there is a mean of three clusters in the rostral SC (Fig. 5A,B) (instead of five clusters in the pigmented strains $\mathrm{C} 3 \mathrm{H}$ and $\mathrm{C} 57 \mathrm{Bl}$; Upton et al., 1999, 2002) with a single medial patch in the caudal SC (Fig. 5C). The contralateral retinal axons are diffusely distributed in the stratum griseum superficiale (SGS) and the SO, leaving no clear gap (Godement et al., 1984; Sachs et al., 1986). In the $b r l$ mice, an abnormal distribution of the ipsilateral retinotectal axons was noted: (1) there was no clustering of the axons into patches at any level of the SC (Fig. 5D,F); (2) there was an increased density of ipsilateral fibers in the lateral and caudal parts of the SC (Fig. 5F); and (3) the ipsilateral retinal terminals extended dorsally into the SGS instead of remaining in the SO; this dorsoventral spread was estimated to be increased by $150 \%$ in comparison with controls (Fig. $5 G ; n=5$ per genotype; ANOVA test, $p<0.05$ ). With CTB labeling, an intermix of axon terminals from both eyes was visible.

Cytoarchitectonic analysis of the SC with Nissl and calbindin 


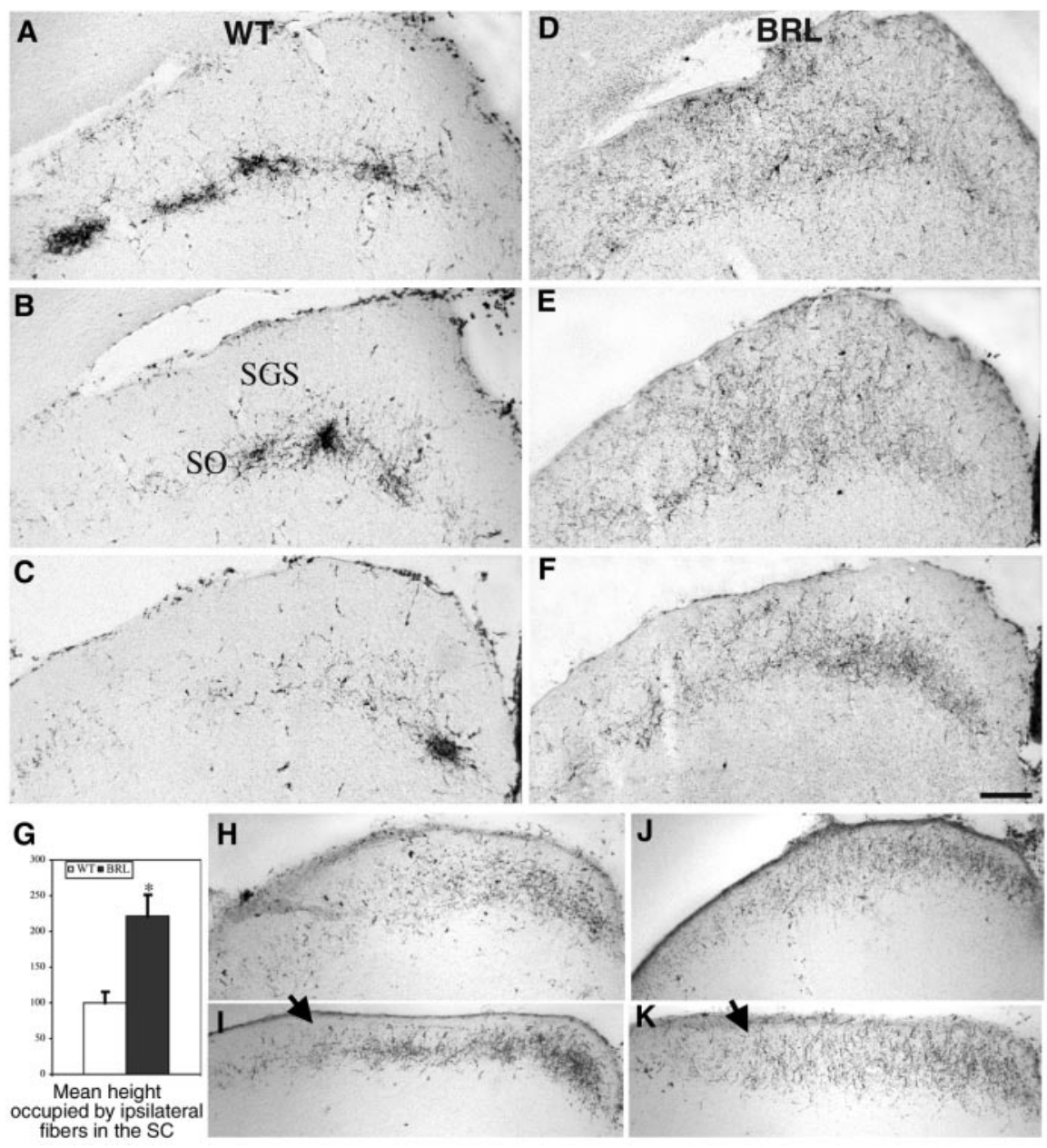

Figure 5. Lack of clustering and abnormal laminar distribution of the ipsilateral retinal projection in the $\mathrm{SC}$ of $\mathrm{br} /$ mice. The retinal projections in the SC were HRP-labeled in 5-week-old $(A-F)$ and P3 $(H-K)$ mice of the WT and br/ strains. $A-C$, In the WT mice, the ipsilateral fibers are clustered in the deep layer of the superior colliculus, the $\mathrm{SO}$, with very few axons entering the upper layer, the SGS. As shown on three coronal sections (spaced by $200 \mu \mathrm{m}$ ) through the SC, four clusters are visible in the rostral SC $(A)$; three clusters are seen at intermediate levels of the $\mathrm{SC}(B)$; and only one is present in the caudal $\mathrm{SC}(C)$. In the brl mice, the ipsilateral fibers do not aggregate as clusters at any level of the SC. The ipsilateral retinal fibers have a broader mediolateral extension in the caudal SC (compare F, C) and invade the SGS. G, The mean height of the ipsilateral retinal axons in the SC was quantified and showed a twofold increase in the br/ mice (black bar) compared with the controls (white bar). Measures were done as follows. The second, fifth, and ninth sections of the complete rostrocaudal series through the SC were photographed; the area containing the HRP labeling was delimited; and the mean height was calculated. The values are normalized relative to controls. Means and SDs are calculated from five cases for each genotype. ${ }^{*}$ Significant difference (ANOVA, $p<0.05$ ). $H-K$, At P3, the ipsilateral retinal fibers are not yet clustered in the WT mice $(H, I)$ in either the rostral $\mathrm{SC}(H)$ or caudal SC $(I)(n=4$ for each genotype). J, $K$, A similar distribution is noted in rostral $(J)$ and caudal $(K)$ sections through the $S C$ of the $b r /$ mice. However, the retinal fibers have a more diffuse extension in the ventrodorsal plane in the $\mathrm{br} /$ mice in comparison with controls (arrow). Scale bar: $A-F, 0.1 \mathrm{~mm} ; H-K, 0.09 \mathrm{~mm}$.

immunocytochemistry showed no detectable changes in the lamination of the SC in the brl mice (data not shown).

Thus, the lack of $\mathrm{AC} 1$ during development alters the general distribution and clustering of the ipsilateral retinal projections and the normal separation of the ipsilateral and contralateral retinal projections in the dLGN and the SC.

\section{Altered segregation of the ipsilateral and contralateral retinal projection is a postnatal event}

To determine when the developmental process is altered in the $b r$ mice, we analyzed the retinal projections in P3 pups $(n=4$ for each genotype) before the normal onset of the segregation of the ipsilateral and contralateral retinal projections (Godement et al., 1984; Upton et al., 1999, 2002). The distribution of the retinal axons in the optic nerve and in the optic chiasm was identical in both genotypes (results not shown). Similarly, there was no visible difference between the $b r l$ and the WT mice in the distribution of retinal axons in the dLGN, where the ipsilateral and contralateral terminals are more diffusely distributed than in the adults (Fig. $4 F, G)$. In the SC, the ipsilateral retinal projection formed a continuous band throughout the deep and superficial SC. Mild differences were noted in the $b r l$ and WT mice. Ipsilateral retinal fibers had already retracted from the superficial strata of the SC in the WT mice (Fig. $5 I$ ) but not in the $b r l$ mice (Fig. $5 \mathrm{~K}$ ); similarly, a mediolateral gradient of the ipsilateral retinal fibers was apparent in the caudal SC of the WT but not the $b r l$ mice (Fig. $5 H-K$ ).

Thus, abnormalities in the distribution of the retinal axons begins postnatally at approximately $\mathrm{P} 3$, coinciding with the retraction of ipsilateral retinal axon terminals from their initially widespread distribution in terminal fields.

\section{Altered topography of the retinotectal and retinothalamic projection}

The abnormal distribution of the ipsilateral and contralateral retinal afferents and their lack of separation into eye-specific domains could result from a defective competitive interaction between the retinal axons from both eyes (for review, see Shatz, 1996). These abnormalities might also be explained by defective signaling of local positional cues within the targets. The retinotectal map obeys a topographic rule that can be simplified as a twocoordinate system: the temporonasal axis of the retina corresponds to the rostrocaudal dimension of the SC, whereas the dorsoventral axis in the retina corresponds to a lateromedial position of terminal axons in the SC (Siminoff et al., 1966) (for review, see Drescher et al., 1997).

We injected small crystals of DiI into the temporal or nasal peripheral retina. Only the cases with small injections labeling 50-100 RGCs (Fig. 6I,J) were analyzed quantitatively $(n=$ 5-7 for each genotype and for each type of dye placement) after sectioning in the sagittal and coronal planes.

After injections in the peripheral temporal retinal axons, a large number of contralateral and a smaller number of ipsilateral RGC axons are labeled. In WT mice, these temporal retinal axons form a dense axon bouquet in the rostral SC (Fig. 6C,E). In the brl mice, the temporal retinal axons either cover the rostral half of the SC (five cases; Fig. 6D) or extend along its entire rostrocaudal extent (two cases; Fig. 6F). We measured the rostrocaudal and mediolateral extent occupied by the RGC terminal axons in similarly sized retinal injections: the projection area was significantly enlarged in the brl mice compared with the WT mice in both dimensions (the individual values for each case are listed in Table 
2). Furthermore, the number of temporal retinal axons extending into the caudal quarter of the SC was significantly increased (Table 2). Terminal arbors formed a loose network compared with the dense focused terminal arbors of the controls, suggesting that there is a reduction in the number of branches formed, in addition to a lack of topographical restriction. This is particularly apparent in cases in which one or two retinal axons projecting to the ipsilateral SC were labeled and could be followed within the plane of one section (Fig. 6G,H).

Crystal dye injections in the nasal retina of WT mice produced a tight cluster of axon terminals in the caudal SC (Fig. $6 \mathrm{~A}$ ). In the brl mice, the projection of the nasal RGCs was normally positioned in the caudal SC, but its mediolateral and rostrocaudal extents were significantly broader and more diffuse than in WT mice (Fig. 6B, Table 2).

To determine the time of appearance of these abnormalities, we did similar temporal dye injections in $\mathrm{P} 2-\mathrm{P} 3$ pups. At that age, the projection pattern of the retinal fibers was comparable in both genotypes, with a wide projection in the SC (data not shown). In the $b r l$ mice, retinal fibers were never seen to meander in abnormal terminal territories such as the inferior colliculus, contrarily to what has been described in ephrin A5-KO mice, for instance (Feldheim et al., 2000).

Converse experiments were performed in which small injections of fluorescent beads were placed in the caudal SC. In these cases, the retrogradely labeled neurons in the retina formed a cluster within the retina of WT mice, with a more diffuse distribution of the retrogradely labeled RGCs noted in the $b r l$ mice (data not shown).

Enlarged terminal fields of retinal axons was also visible in the thalamus. This was analyzed on cases with small temporal retinal injections ( $n=4$ for each genotype), similar to those used for the retinotectal analysis, except that the brains were sectioned in the coronal plane. Carbocyanine-labeled fibers from the temporal retina were found in the ventral and medial part of the dLGN, forming a narrow tight cluster of terminals (Fig. 7A-C). In the $b r l$ mice, the axons originating from similar locations in the retina were localized in the same medioventralcaudal sector of the contralateral dLGN but were more diffusely distributed, forming a loose network that covered a large extent of the dLGN in the plane of the section (Fig. $7 D-F$ ) and extended on two or three sections (140 $\mu \mathrm{m}$ thick) rather than being focused to one section in controls.

These anterograde tracer analyses indicate that although the general targeting of the retinal projection is maintained in the $b r l$ mice, there is a profound alteration in the refinement of the terminal arborization pattern within a given area. These abnormalities are most marked in the case of the temporal retinal axons that project both ipsilaterally and contralaterally. Interestingly, the abnormal spread of the fibers in the target field is not skewed toward one direction but concerns a refinement process that occurs in both the rostrocaudal and mediolateral dimensions. Finally, these abnormalities emerge at a late stage in the formation of the map (after P3) and appear to involve the lack of elimination of abnormally localized axons (e.g., temporal axons are maintained in the caudal SC), as well as a deficit in the elaboration of a focused axon arbors (diffuse terminal fields).

\section{Normal density but ectopic position of ipsilateral RGCs in the brl retina}

cAMP is known to modulate cell proliferation and cell death in the retina (Meyer-Franke et al., 1995; Rehen et al., 1996). One possible explanation for the exuberant distribution of the ipsilat-
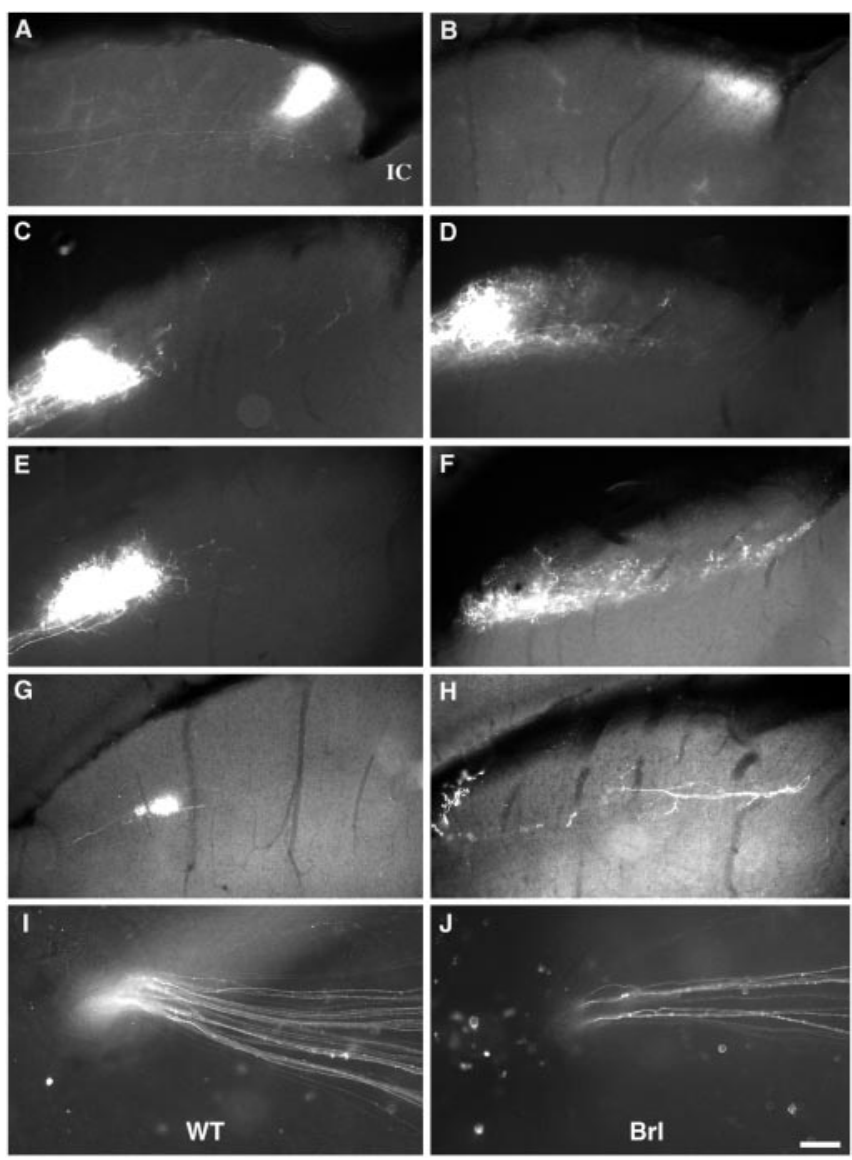

Figure 6. Altered retinotopic projections in the retinotectal system of the brl mice. Small crystals of Dil were placed in the nasal retina $(A, B)$ or the temporal retina $(C-J)$ in WT mice $(A$, $C, E, G)$ and in $b r /$ mice $(B, D, F, H)$. Cases in which only a small amount of $R G C$ axons were labeled $(I, J)$, were selected for analysis. Serial Vibratome sagittal sections (140 $\mu \mathrm{m}$ thick) were made through the $S C$ to measure the extent of the nasal or the temporal retinal projections. In the micrographs of the $S C$, rostral is to the left. $A, B$, Nasal $\mathrm{RGC}$ project in the caudal part of the contralateral SC in both WT mice $(A)$ and $b r /$ mice $(B)$. In the $b r l$ mice, the projection is much more loosely distributed than in the WT mice and occupies a significantly wider area (see quantifications in Table 2). (-F, Temporal RGCS to the contralateral SC are clustered in the rostral part of the $S C$, with only a few labeled fibers extending caudally to this patch in WT mice, for which two different cases are illustrated $(C, E)$. In this br/ mouse $(D, F)$, the temporal retinal projection is less dense and extends to occupy the rostral half of the $S C$ in some cases $(D)$ or its entire rostrocaudal extent in other cases $(F) . G, H$, Projections from the temporal retina to the ipsilateral SC are scarce, generally limited to one or two fibers, which form a dense cluster in WT mice $(G)$, or are spread out in the $b r l$, with only a few collateral branches $(H) . I, J$, Dil injections in the retina corresponding to the cases in $E$ and $F$ are shown to illustrate the small number of the labeled RGCs that converge toward the optic disk. Scale bar: $A-F, 0.1 \mathrm{~mm} ; G-H, 0.05 \mathrm{~mm}$.

eral retinal projections in the $b r l$ mice could be related to an abnormal development of the RGCs in the retina. The maturation of the retinal projections coincides with cell death of $\sim 50-$ $70 \%$ of the RGCs [hamster (Insausti et al., 1984) and mouse (Young, 1984; Strom and Williams, 1998)]. However, we found no visible difference in the distribution of RGCs between the $b r l$ and WT mice: RGCs were distributed as a monolayer with similar densities in both genotypes (Fig. $8 \mathrm{~A}$ ). To estimate the number of RGCs projecting ipsilaterally or contralaterally, we did massive injections of FG in the optic tract at the level of the dLGN ( $n=5$ per genotype). Contralaterally projecting RGCs that constitute $\sim 98 \%$ of the RGCs (as estimated by Drager and Olsen, 1980) cover the entire surface of the retina (results not shown) and have similar densities in the control and the $b r l$ mice (Table 3), with a total estimated number of $32,000-35,000$ cells per retina. The 
Table 2. Quantification of the contralateral projection of the nasal and temporal retina in wild-type and br/ mice

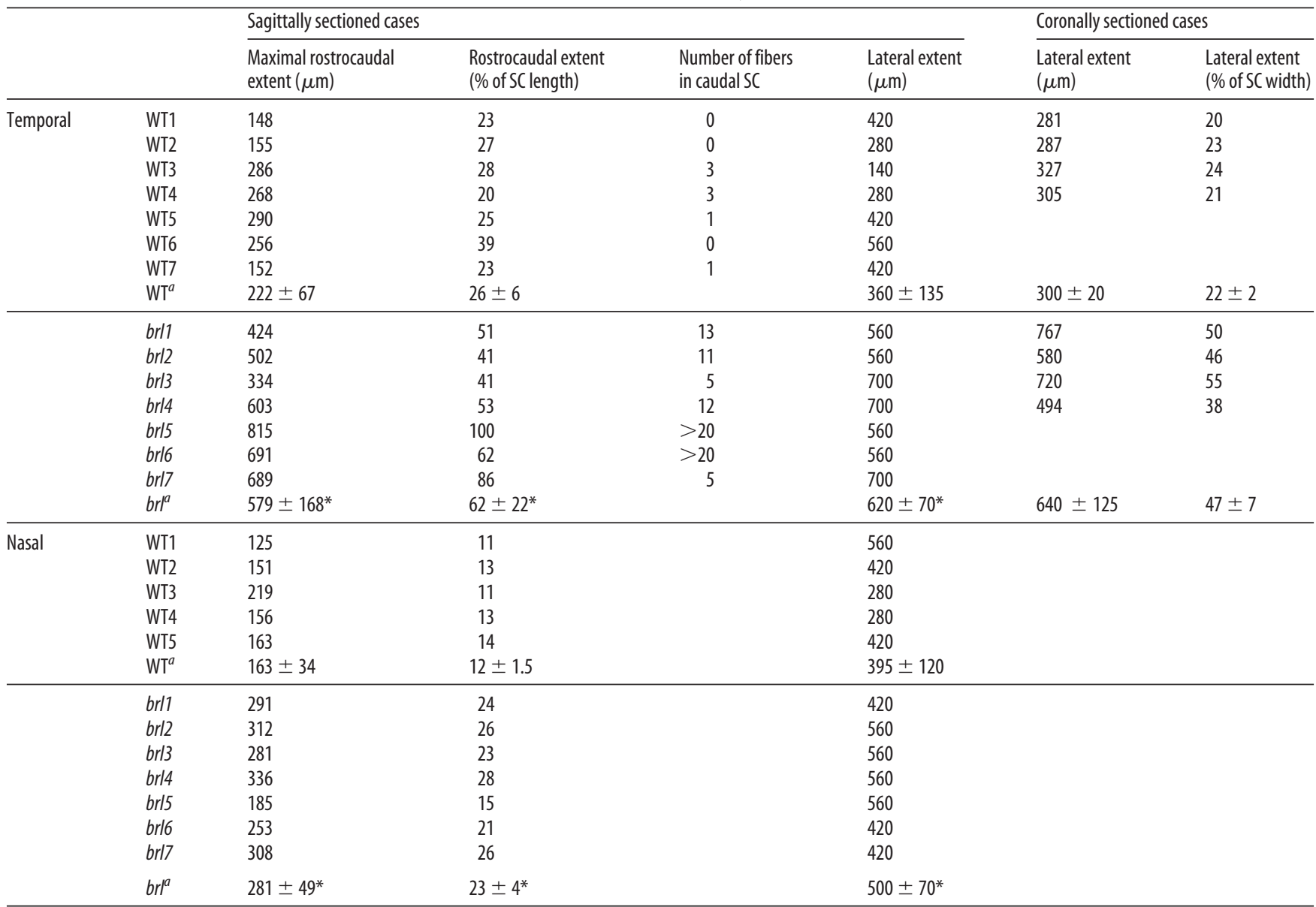

The maximal rostrocaudal length was measured from the serial sagittal sections, and the proportion of this length to the entire $\mathrm{SC}$ extent was calculated. The lateral extension was estimated on sagittal sections as the number of $140 \mathrm{~mm}$ sections in which labeling was visible. The lateral extent was also measured directly on the serial coronal sections.

${ }^{a}$ Values are means $\pm S D$.

*If significant with ANOVA, $p=0.05$

ipsilateral RGCs are concentrated in a ventrotemporal crescent (Fig. 8 B, black area) that covers $16-17 \%$ of the surface of the retina with an estimated total of 1100 ipsilateral RGCs (Table 3). In addition, there are a few neurons with an ectopic position outside the crescent spread out in the central and nasal retina (mean, $15 \pm 5$ per retina). In the $b r l$ mice there was no significant change in the density of the ipsilateral RGCs within the temporoventral crescent, but the number of "ectopic" ipsilaterally projecting RGCs (outside the crescent) was increased fourfold (mean, $77 \pm 5$ per retina; Fig. $8 B$, Table 3 ). However, these ectopic RGCs represent only $3 \%$ of the total ipsilateral RGC component, in agreement with previous estimates (Godement et al., 1987; Upton et al., 1999), explaining why the total amount of ipsilaterally projecting RGCs is not significantly modified in the brl mice. When analyzing retrograde labeling of RGCs in P3 WT pups $(n=3)$, we observed a similar distribution of the ipsilateral RGCs, with 70-80 RGCs outside the dense crescent. This corresponds quite precisely to the number of ectopic cells encountered in the adult $b r l$ retinas (Table 3 ).

These experiments indicate that the total number of RGCs is unchanged in the retina of the $\mathrm{brl}$ mice, suggesting that the developmental cell death is not substantially modified by the AC1 deficiency. However, a number of RGCs with an abnormal topographic localization, which are transiently present during early development, are not eliminated in the $b r l$ mice.

\section{Discussion}

The present results indicate that AC1 plays an essential role in the development of the normal topographic retinal projection maps in the SC and the dLGN. This involves an action of AC1 during the phase of activity-dependent refinement of the map, whereas early developmental events, such as the guidance of RGC axons to their targets, and cell survival are not affected.

\section{Lack of functional redundancy of the calcium-dependent ACs in the developing retina}

The finding that $\mathrm{AC} 1$ inactivation suffices to disrupt the normal development of neural connections in the visual system and in the cerebral cortex (Welker et al., 1996; this study) indicates that there is little functional redundancy of the different AC isoenzymes during development. Thus, although AC1 appears to contribute to a rather small fraction of the total AC activity, it could have a unique function during development. Each AC has been shown to have a specific localization and mode of activation by G-protein subunits, variations in the level of calcium ions, or both (Pieroni et al., 1993; Cooper et al., 1995; Wong et al., 1999). However, among the different ACs identified, the AC1 and AC8 isoforms share the particularity of being directly activated by raised calcium levels and could functionally compensate one another in structures where both genes are expressed (Xia et al., 1991; Cali et al., 1994; Villacres et al., 1998; Schaefer et al., 2000). 

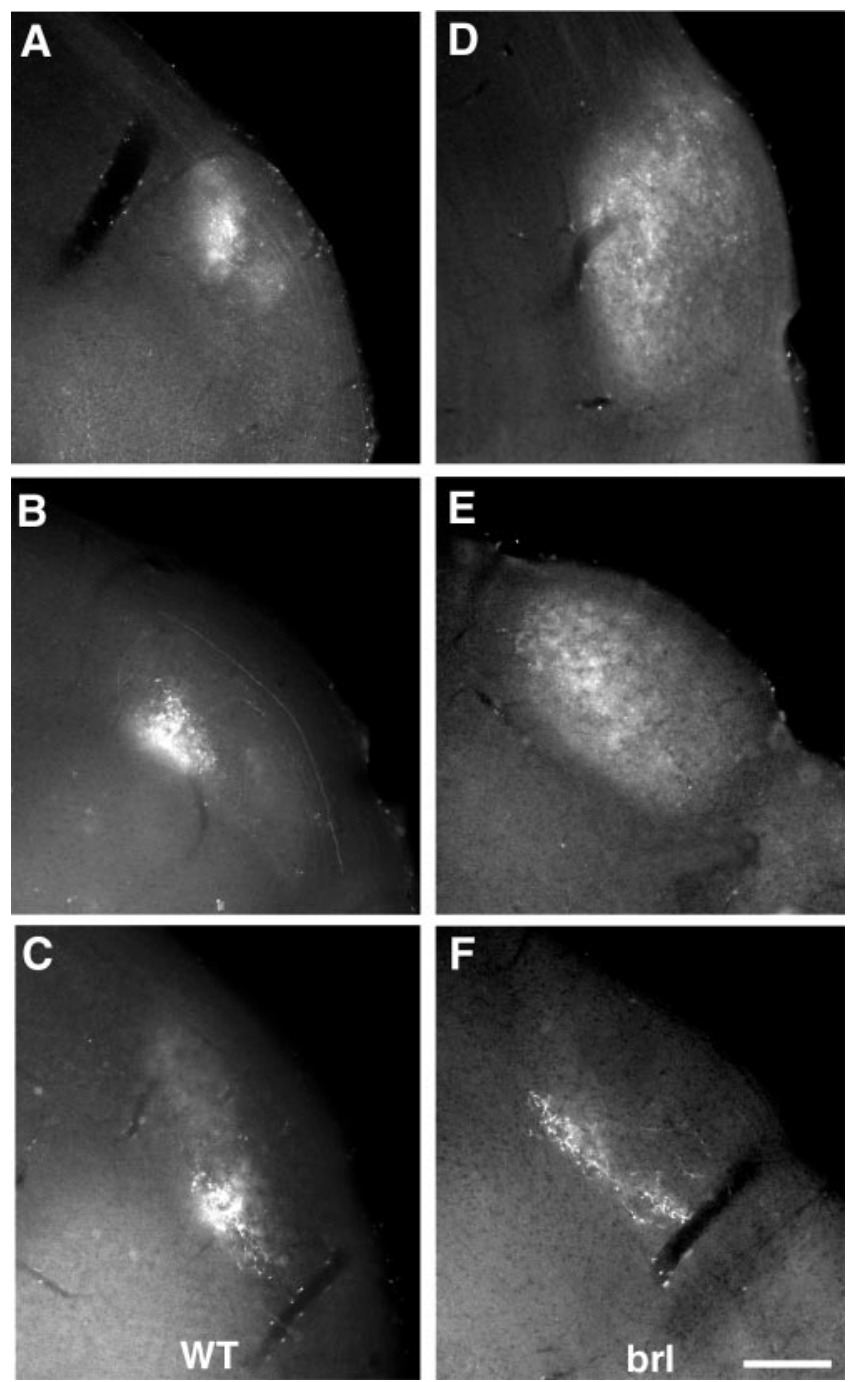

Figure 7. Lack of focusing of retinotopic projections in the dLGN of the brl mice. Small crystals of Dil were placed in the temporal retina, and the contralateral dLGN was examined on coronal sections in WT mice $(A-C)$ and brl mice $(D-F)$. Three different cases are illustrated. In all WT cases $(A-C)$, the projection formed by the temporal retinal axons forms a dense patch in the medioventral part of the dLGN. In the brl cases, with similarly sized injections in the retina, the terminal field occupies a larger extent of the $\mathrm{dLGN}(D, E)$ and appears to be more scattered (F). Scale bar, $155 \mu \mathrm{m}$.

The compensation between these two genes has been indicated by genetic studies. AC1-AC8-double-KO mice have deficits in longterm potentiation (LTP) and long-term memory that do not exist in the single AC1- or AC8-KO mice (Wong et al., 1999). In the developing visual system, we find that $\mathrm{AC} 1$ is the only calciumstimulated AC in the RGCs, whereas the AC8 gene is expressed in the SC. Thus, the specificity of the action of AC1 in this system
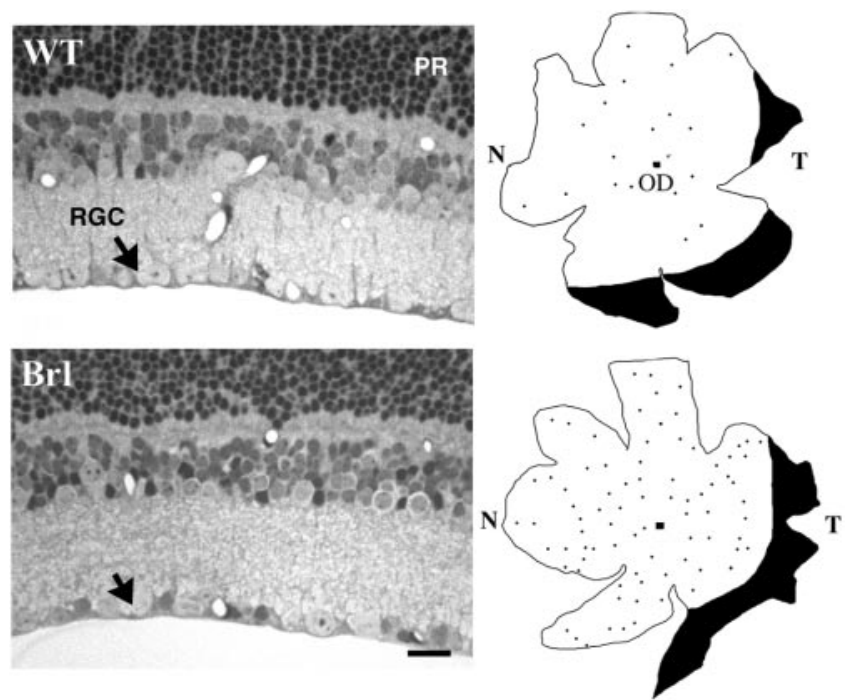

Figure 8. Distribution of RGCs in the retina of adult WT and $b r$ mice. A, Semithin thick transverse sections ( $1 \mu \mathrm{m}$ thick stained with toluidine blue) through the adult retinas of WT mice (top) and brl mice (bottom). The RGCs layer is noted with an arrow; the outer layer (photoreceptors) is at the top. In both the WT retinas (top) and the brl retinas (bottom), the RGCs (arrows) are distributed as a continuous monolayer. Scale bar, $5 \mu \mathrm{m}$. B, Distribution of the ipsilateral RGCs. Camera lucida drawings of the flattened retinas of adult WT and brl mice after fluorogold injections in the ipsilateral optic tract are shown. Most of the ipsilaterally projecting cells are localized in a ventrotemporal crescent (black) covering a similar size in both genotypes. RGCS situated outside this crescent were plotted individually. A fourfold to fivefold increase of these ectopic ipsilateral RGCs was noted in the brl mice (Table 3). OD, Optic disk; $N$, nasal; $T$, temporal. Dorsal is at the top.

appears to be primarily determined by its cellular localization. The invalidation of the AC1 gene in the brl mutants (Abdel-Majid et al., 1998) is likely to essentially affect the function of the RGCs, whereas in the SC neurons, the loss of AC1 function is likely compensated by AC8. Moreover, it is possible, although not yet demonstrated, that different isoforms of the membrane-bound ACs have different subcellular localization (Mons and Cooper, 1995). On the basis of comparison of in situ hybridization and biochemical measures of AC activity, our data suggest that AC1 could be, at least in part, addressed in the axon terminals. This hypothesis will require direct confirmation with immunocytochemical analyses when specific antibodies to AC1 become available. For the time being, ultrastructural localization of ACs has only been done with antibodies that recognize all the AC isoforms showing essentially a dendritic localization (Mons et al., 1995). However, the notion that AC1 may be presynaptic is compatible with electrophysiological studies indicating that AC1 controls presynaptic release mechanisms (Weisskopf et al., 1994; Villacres et al., 1998).

Table 3. Density and distribution of RGCs in WT and br/ mice

\begin{tabular}{|c|c|c|c|c|c|}
\hline & $\begin{array}{l}\text { Density of } \\
\text { contra RGCs } \\
\text { (cells/ } \mu \mathrm{m}^{2} \text { ) }\end{array}$ & $\begin{array}{l}\text { Density of ipsilateral } \\
\mathrm{RGCs} \text { in the crescent } \\
\left(\text { cells } / \mu \mathrm{m}^{2}\right)\end{array}$ & $\begin{array}{l}\text { Relative area of } \\
\text { ventrotemporal } \\
\text { crescent ( } \% \text { of retina) }\end{array}$ & $\begin{array}{l}\text { Number of ipsilateral RGCS } \\
\text { in the crescent }\end{array}$ & $\begin{array}{l}\text { Number of ectopic } \\
\text { ipsilateral RGCs }\end{array}$ \\
\hline $\mathrm{WT}(n=4)$ & $1995 \pm 265$ & $392 \pm 26$ & $17.3 \pm 0.7$ & $1100 \pm 70$ & $15 \pm 5$ \\
\hline$b r l(n=7)$ & $\begin{array}{l}2195 \pm 177 \\
\text { (NS) }\end{array}$ & $\begin{array}{l}413 \pm 25 \\
(\mathrm{NS})\end{array}$ & $\begin{array}{l}16.3 \pm 1.6 \\
\text { (NS) }\end{array}$ & $\begin{array}{l}1150 \pm 177 \\
\text { (NS) }\end{array}$ & $76 \pm 5^{*}$ \\
\hline WT P3 $(n=3)$ & & & & & $80 \pm 5^{*}$ \\
\hline
\end{tabular}

Values are means \pm SD. NS, Nonsignificant.

*If significantly different from controls with ANOVA, $p=0.05$. 


\section{Loss of AC1 affects only late developmental events}

A striking effect of cyclic nucleotides, at least in vitro, is to modify the response of growth cones to repulsive and attractive cues (Song et al., 1997, 1998). Our observations in the $b r l$ mice indicate that AC1 is not essential for the initial establishment of the retinal projections. The crossing of retinal axons at the optic chiasm or the selection of appropriate central targets appeared unaltered in the mutants. It is possible that other ACs, such as AC2 and AC5, which are also expressed in the RGCs at the right time (X. Nicol, A. Ravary, and P. Gaspar, unpublished observations), could act to maintain normal cAMP levels in the RGCs. Total AC activity was not modified in the retina of the $\mathrm{brl}$ mice, indicating that the general capacity to produce cAMP is not compromised despite the fact that coupling of cAMP production to calcium is altered. The residual cAMP production in mutants could be sufficient to allow retinal growth cones to read out the chemotactic guidance cues during retinal axon guidance (Dingwell et al., 2000) and to sustain RGC survival (Meyer-Franke et al., 1995), because the AC1-knock-out mice showed no increased developmental cell death in the retina. These results indicate that, in vivo, a tight control of cAMP levels in relationship to calcium increase is not essential for axon tract guidance or for cell survival in the visual system.

On the other hand, AC1 appears to have an essential function for the remodeling of the retinal maps. Maps are initially imprecise; the ipsilateral and contralateral retinal axons separate from one another during the first postnatal week (Godement et al., 1984; Upton et al., 1999); and the retinotopic positioning of RGC axons in the SC is acquired progressively during the same period; temporal RGCs axons retract from the caudal SC and elaborate novel axon branches in the rostral SC (Simon and O'Leary, 1992). A similar refinement of the projection exists along the mediolateral dimension (Hindges et al., 2002). In the brl mice, these processes appear to be defective, leading to the stabilization of RGC axon branches in abnormal positions along the rostrocaudal and mediolateral axis of the SC. Similarly, projections from the ipsilateral retina are abnormally stabilized in areas of the SC and the dLGN from where they are normally eliminated. This is caused by the maintenance of a transient ipsilateral retinal projection from the central and nasal portions of the retina (O'Leary et al., 1986; Godement et al., 1987) in addition to a lack of elimination of abnormally placed retinal side branches. In addition to these altered regressive processes, there appears to be a defect in the axon terminal elaboration, as suggested by the reduced density of terminals in the dLGN and SC. Thus, although the approximate positioning of retinal maps appears to be normally established in the $b r l$ mice, the fine-grained retinotopic positioning of the retinal terminals is never attained. Similar abnormalities have been noted in the somatosensory cortex of the brl mice in which thalamocortical axon terminal arbors are wider than in WT mice, extending over as much as 10 adjacent barrel domains (Welker et al., 1996). However the effects of AC1 deletion may be different in both systems, because in the barrel system, AC1 is expressed both in the thalamus and the cerebral cortex (Matsuoka et al., 1997; present observations), whereas in the retinotectal system, the RGCs can be designated as the main culprits.

The alterations of axon branching and elimination in both systems could result from a defective readout of trophic or local positional indices within central targets during a late phase of axonal growth. Recently, the role of ephrins has been highlighted in these processes (Flanagan and Vanderhaeghen, 1998). It will thus be of interest to determine whether lack of AC1 interferes with the signaling of these late positional signals.
A consequence of AC1 dysfunction could also be a modification of activity-dependent mechanisms, either by an alteration of the production of spontaneous neural activity in the retina or by modulating long-term activity-dependent changes in the developing circuits. The importance of the retinal waves of spontaneous activity has been emphasized by a number of studies (Penn et al., 1998; Rossi et al., 2001), and because the levels of cAMP modify the spatiotemporal characteristics of the retinal waves (Stellwagen et al., 1999), it is possible that AC1 deficiency could disorganize this spontaneous neural activity.

Another possibility would be that the lack of AC1 interferes with long-lasting enhancement of synaptic transmission at the retinotectal synapse. cAMP has been implicated in plasticity and in LTP (Frey et al., 1993; Huang et al., 1994; Pham et al., 2001). Available evidence in the AC1-KO mice indicates that $\mathrm{ACl}$ is primarily involved in presynaptic LTP, at least in the hippocampus and the cerebellum (Abrams et al., 1991; Storm et al., 1998; Villacres et al., 1998). Similar presynaptic potentiation can thus reasonably be expected to occur at the developing retinal synapse. We have previously shown the importance of presynaptic mechanisms during the reorganization of the retinal maps; excessive activation or lack of the 5-HT1B receptor, which is localized presynaptically on retinal axons, causes alterations in the normal refinement the retinal map (Salichon et al., 2001, Upton et al., 2002). Similarly, excess activation of the 5-HT1B receptor on the thalamocortical axons causes an altered refinement of the thalamocortical axon arbors in the barrel field (Rebsam et al., 2002). Because the signaling pathway of 5-HT1B receptors involves negative coupling to AC, it is possible that these molecules converge toward similar downstream mechanisms.

Whatever the exact cellular mechanisms, our study underlies the importance of $\mathrm{AC} 1$ for the normal refinement of the retinal projections. Because AC1 allows tight coupling between calcium increase and cAMP production, it could be an important link between the neural activity generated in the RGCs and the structural changes of these neurons during development.

\section{References}

Abdel-Majid RM, Leong WL, Schalkwyk LC, Smallman DS, Wong ST, Storm DR, Fine A, Dobson MJ, Guernsey DL, Neumann PE (1998) Loss of adenylate cyclase I activity disrupts patterning of mouse somatosensory cortex. Nat Genet 19:289-291.

Abrams TW, Karl KA, Kandel ER (1991) Biochemical studies of stimulus convergence during classical conditioning in Aplysia: dual regulation of adenylate cyclase by $\mathrm{Ca}^{2+} /$ calmodulin and transmitter. J Neurosci 11:2655-2665.

Brooks SP, Storey KB (1992) Bound and determined: a computer program for making buffers of defined ion concentrations. Anal Biochem 201:119-126.

Cai D, Qiu J, Cao Z, McAtee M, Bregman BS, Filbin MT (2001) Neuronal cyclic AMP controls the developmental loss in ability of axons to regenerate. J Neurosci 21:4731-4739.

Cali JJ, Zwaagstra JC, Mons N, Cooper DM, Krupinski J (1994) Type VIII adenylate cyclase: a $\mathrm{Ca}^{2+} /$ calmodulin-stimulated enzyme expressed in discrete regions of rat brain. J Biol Chem 269:12190-12195.

Constantine-Paton M, Cline HT (1998) LTP and activity-dependent synaptogenesis: the more alike they are, the more different they become. Curr Opin Neurobiol 8:139-148.

Cooper DM, Mons N, Karpen JW (1995) Adenylate cyclases and the interaction between calcium and cAMP signalling. Nature 374:421-424.

Dingwell KS, Holt CE, Harris WA (2000) The multiple decisions made by growth cones of RGCs as they navigate from the retina to the tectum in Xenopus embryos. J Neurobiol 44:246-259.

Drager UC, Olsen JF (1980) Origins of crossed and uncrossed retinal projections in pigmented and albino mice. J Comp Neurol 1:383-412.

Drescher U, Bonhoeffer F, Muller BK (1997) The Eph family in retinal axon guidance. Curr Opin Neurobiol 7:75-80. 
Feldheim DA, Kim YI, Bergemann AD, Frisen J, Barbacid M, Flanagan JG (2000) Genetic analysis of ephrin-A2 and ephrin-A5 shows their requirement in multiple aspects of retinocollicular mapping. Neuron 25:563-574

Flanagan JG, Vanderhaeghen P (1998) The ephrins and Eph receptors in neural development. Annu Rev Neurosci 21:309-345.

Frey U, Huang YY, Kandel ER (1993) Effects of cAMP simulate a late stage of LTP in hippocampal CA1 neurons. Science 260:1661-1664.

Godement P, Salaun J, Imbert M (1984) Prenatal and postnatal development of retinogeniculate and retinocollicular projections in the mouse. J Comp Neurol 230:552-575.

Godement P, Salaun J, Metin C (1987) Fate of uncrossed retinal projections following early or late prenatal monocular enucleation in the mouse. J Comp Neurol 255:97-109.

Huang YY, Li XC, Kandel ER (1994) cAMP contributes to mossy fiber LTP by initiating both a covalently mediated early phase and macromolecular synthesis-dependent late phase. Cell 79:69-79.

Hindges R, McLaughlin T, Genoud N, Henkemeyer M, O’Leary DD (2002) EphB forward signaling controls directional branch extension and arborization required for dorsal-ventral retinotopic mapping. Neuron 35:475-487.

Insausti R, Blakemore C, Cowan WM (1984) Ganglion cell death during development of ipsilateral retino-collicular projection in golden hamster. Nature 308:362-365.

LaVail JH, Nixon RA, Sidman RL (1978) Genetic control of retinal ganglion cell projections. J Comp Neurol 182:399-421.

Lebrand C, Cases O, Wehrle R, Blakely RD, Edwards RH, Gaspar P (1998) Transient developmental expression of monoamine transporters in the rodent forebrain. J Comp Neurol 401:506-524.

Mason C, Erskine L (2000) Growth cone form, behavior, and interactions in vivo: retinal axon pathfinding as a model. J Neurobiol 44:260-270.

Matsuoka I, Suzuki Y, Defer N, Nakanishi H, Hanoune J (1997) Differential expression of type I, II, and V adenylate cyclase gene in the postnatal developing rat brain. J Neurochem 68:498-506.

Meyer-Franke A, Kaplan MR, Pfrieger FW, Barres BA (1995) Characterization of the signaling interactions that promote the survival and growth of developing retinal ganglion cells in culture. Neuron 15:805-819.

Meyer-Franke A, Wilkinson GA, Kruttgen A, Hu M, Munro E, Hanson Jr MG, Reichardt LF, Barres BA (1998) Depolarization and cAMP elevation rapidly recruit TrkB to the plasma membrane of CNS neurons. Neuron 21:681-693.

Mons N, Cooper DM (1995) Adenylate cyclases: critical foci in neuronal signaling. Trends Neurosci 18:536-542.

Muir-Robinson G, Hwang BJ, Feller MB (2002) Retinogeniculate axons undergo eye-specific segregation in the absence of eye-specific layers. J Neurosci 22:5259-5264.

O'Leary DDM, Fawcett JW, Cowan M (1986) Topographic targeting errors in the retinocollicular projection and their elimination by selective axon cell death. J Neurosci 6:3692-3705.

Penn AA, Riquelme PA, Feller MB, Shatz CJ (1998) Competition in retinogeniculate patterning driven by spontaneous activity. Science 279: 2108-2112.

Pham TA, Rubenstein JL, Silva AJ, Storm DR, Stryker MP (2001) The CRE/ CREB pathway is transiently expressed in thalamic circuit development and contributes to refinement of retinogeniculate axons. Neuron 31:409-420.

Pieroni JP, Jacobowitz O, Chen J, Iyengar R (1993) Signal recognition and integration by Gs-stimulated adenylate cyclases. Curr Opin Neurobiol 3:345-351.

Quintyn JC, Ferrari P, Wasowicz MO, Nguyen-Legros J, Verseaux-Botteri C (1999) Les adénylates cyclases dans la rétine du rat. In: Les séminaires ophtalmologiques Fondation Ipsen, Vol 11 (Chisten Y, Doly M, DroyLefaix MT, eds), pp 203-213. Paris: Irvinne.

Rebsam A, Seif I, Gaspar P (2002) Refinement of thalamocortical arbors and emergence of barrel domains in the primary somatosensory cortex: a study of normal and monoamine oxidase a knock-out mice. J Neurosci 22:8541-8552.

Rehen SK, Varella MH, Freitas FG, Moraes MO, Linden R (1996) Contrasting effects of protein synthesis inhibition and of cyclic AMP on apoptosis in the developing retina. Development 122:1439-1448.

Rossi FM, Pizzorusso T, Porciatti V, Marubio LM, Maffei L, Changeux JP (2001) Requirement of the nicotinic acetylcholine receptor beta 2 sub- unit for the anatomical and functional development of the visual system. Proc Natl Acad Sci USA 98:6453-6458.

Sachs GM, Jacobson M, Caviness Jr VS (1986) Postnatal changes in arborization patterns of murine retinocollicular axons. J Comp Neurol 246:395-408.

Salichon N, Gaspar P, Upton AL, Picaud S, Hanoun N, Hamon M, De Maeyer E, Murphy DL, Mossner R, Lesch KP, Hen R, Seif I (2001) Excessive activation of serotonin (5-HT) $1 \mathrm{~B}$ receptors disrupts the formation of sensory maps in monoamine oxidase A and 5-HT transporter knock-out mice. J Neurosci 21:884-896.

SalomonY, Londos C, Rodbell M (1974) A highly sensitive adenylate cyclase assay. Anal Biochem 58:541-548.

Schaefer ML, Wong ST, Wozniak DF, Muglia LM, Liauw JA, Zhuo M, Nardi A, Hartman RE, Vogt SK, Luedke CE, Storm DR, Muglia LJ (2000) Altered stress-induced anxiety in adenylate cyclase type VIII-deficient mice. J Neurosci 20:4809-4820.

Shatz CJ (1996) Emergence of order in visual system development. J Physiol (Paris) 90:141-150.

Siminoff R, Schwassmann HO, Kruger L (1966) An electrophysiological study of the visual projection to the superior colliculus of the rat. J Comp Neurol 127:435-444.

Simon DK, O'Leary DD (1992) Development of topographic order in the mammalian retinocollicular projection. J Neurosci 12:1212-1232.

Song HJ, Ming GL, Poo MM (1997) cAMP-induced switching in turning direction of nerve growth cones. Nature 388:275-279.

Song H, Ming G, He Z, Lehmann M, McKerracher L, Tessier-Lavigne M, Poo M (1998) Conversion of neuronal growth cone responses from repulsion to attraction by cyclic nucleotides. Science 281:1515-1518.

Stellwagen D, Shatz CJ (2002) An instructive role for retinal waves in the development of retinogeniculate connectivity. Neuron 33:357-367.

Stellwagen D, Shatz CJ, Feller MB (1999) Dynamics of retinal waves are controlled by cyclic AMP. Neuron 24:673-685.

Storm DR, Hansel C, Hacker B, Parent A, Linden DJ (1998) Impaired cerebellar long-term potentiation in type I adenylate cyclase mutant mice. Neuron 20:1199-1210.

Strom RC, Williams RW (1998) Cell production and cell death in the generation of variation in neuron number. J Neurosci 18:9948-9953.

Upton AL, Salichon N, Lebrand C, Ravary A, Blakely R, Seif I, Gaspar P (1999) Excess of serotonin (5-HT) alters the segregation of ispilateral and contralateral retinal projections in monoamine oxidase A knock-out mice: possible role of 5-HT uptake in retinal ganglion cells during development. J Neurosci 19:7007-7024.

Upton AL, Ravary A, Salichon N, Moessner R, Lesch K-P, Hen R, Seif I, Gaspar P (2002) Lack of 5-HT1B receptor and of serotonin transporter have different effects on the segregation of retinal axons in the lateral geniculate nucleus compared to the superior colliculus. Neurosci 111:567-610.

Van der Loos H, Welker E, Dorfl J, Rumo G (1986) Selective breeding for variations in patterns of mystacial vibrissae of mice. Bilaterally symmetrical strains derived from ICR stock. J Hered 77:66-82.

Villacres EC, Wong ST, Chavkin C, Storm DR (1998) Type I adenylate cyclase mutant mice have impaired mossy fibre long-term potentiation. J Neurosci 18:3186-3194.

Weisskopf MG, Castillo PE, Zalutsky RA, Nicoll RA (1994) Mediation of hippocampal mossy fibre long-term potentiation by cyclic AMP. Science 265:1878-1882.

Welker E, Armstrong-James M, Bronchti G, Ourednik W, GheorghitaBaechler F, Dubois R, Guernsey DL, Van der Loos H, Neumann PE (1996) Altered sensory processing in the somatosensory cortex of the mouse mutant barrelless. Science 271:1864-1867.

Wilkinson DG (2001) Multiple roles of EPH receptors and ephrins in neural development. Nat Rev Neurosci 2:155-164.

Wong ST, Athos J, Figueroa XA, Pineda VV, Schaefer ML, Chavkin CC, Muglia LJ, Storm DR (1999) Calcium-stimulated adenylate cyclase activity is critical for hippocampus-dependent long-term memory and late phase LTP. Neuron 23:787-798.

Xia ZG, Refsdal CD, Merchant KM, Dorsa DM, Storm DR (1991) Distribution of mRNA for the calmodulin-sensitive adenylate cyclase in rat brain: expression in areas associated with learning and memory. Neuron 6:431-443.

Young RW (1984) Cell death during differentiation of the retina in the mouse. J Comp Neurol 229:362-373. 